\title{
Systemic Approach to the New Production Research Challenges
}

\author{
(Anthony) Shun Fung Chiu ${ }^{a, b, *}$, Luis E. Quezadac, Kim Hua Tand, Sergio E. Gouvea da Costa ${ }^{e}$, \\ Industrial \& Systems Engineering, De La Salle University, Manila, Philippines \\ 'Institute of Innovation and Circular Economy, Asia University, Taichung, R.O.C. \\ 'Department of Industrial Engineering, University of Santiago of Chile, Chile \\ dNottingham University Business School, Jubilee Campus, UK \\ ePontifícia Universidade Católica do Paraná, Brazil \\ Universidade Tecnológica Federal do Paraná (UTFPR), Campus Pato Branco, Brazil \\ ${ }^{*}$ Corresponding Author. Industrial and Systems Engineering, De La Salle University, Manila and Institute of Innovation and Circular Economy, Asia \\ University, Taichung. \\ Email address: anthony.chiu@dlsu.edu.ph (A.S.F.Chiu)
}

\begin{abstract}
This virtual special issue highlights emerging production research challenges alongside a systemic approach in forms of novel contributions in literature review, thematic analyses, and methodological advances. The selected articles provide insights on how new production research challenges bring about opportunities for growth in sub-fields of supply chain networks, new product development, environmental and economically viable issues, service value chain, and machine learning among others. In this article, an overview of key organizational characteristics as well as significant theoretical ideas and practical applications to production research issues are presented. Future directions in the production research domain are also provided.
\end{abstract}

\section{Introduction}

As the operational strategies involved in the general production research continue to advance, relevant issues and new challenges also begin to arise. As such, the need to further develop theoretical foundations and solution approaches becomes a major pressing concern for stakeholders particularly for managers and decision-makers in both the manufacturing and service sectors. When issues and challenges are established clearly in literature, formulation of sound strategies and policies is expected to be directed toward relatively urgent and suitable platforms. Correspondingly, taking important points of discussion on supply chain finance, lean and green manufacturing, sustainable development and performance of firms, among others; shall promote a more diverse analysis related to the inherent relationships among supply chain actors, quality metrics, and customer satisfaction which leads to a wider, holistic take of the current issues and advances in the field.

Thus, this virtual special issue (VSI) for the 24th International Conference on Production Research (ICPR) held in Poznan, Poland works under the theme: New challenges for production research. Specifically, this VSI selected 25 papers that contribute to both the theoretical and practical perspectives bring about significant insights on production research areas as in advanced manufacturing processes and systems, sustainable manufacturing, manufacturing management, and support and service processes. These papers provided an opportunity for scholars and practitioners alike to understand the relevant issues in production research with primary focus thematic concerns as well as its corresponding solution approaches. It is also noteworthy to emphasize that other than outstanding implications drawn by these papers, novel contributions were also made for the purpose of linking existing theories in extant literature with real-world phenomena on the supply chain in particular. Several other papers also modified and extended methodologies in order to capture a wider scope and a more comprehensive aspect of quality control and monitoring in production processes, including geographical dimensions.

The succeeding sections aim to give information to the readers on the selected research that best represents the goals of this VSI. Here, the audience can find highlights as processed by the authors among review papers, thematic-based papers with a strong accent on 
relevant production research issues and challenges, papers that present solution approaches and finally papers with prominent theoretical and industrial implications.

\section{Review papers on new challenges for production research}

For this VSI, two review papers provided a comprehensive and deeper understanding of manufacturing management particularly in the area of lean manufacturing systems, supply chain management, and manufacturing strategies. These review papers exposed the readers to relevant approaches to sustainable service solutions and improved efficiency and performance in both theoretical and practical perspectives.

Chakuu et al. (2019) focused on characterizing supply chain finance (SCF) instruments which can be implemented to improve the performance of processes and finances in the supply chain. A systematic literature review was conducted with an emphasis on addressing key review questions such as the SCF instruments that different actors can implement to improve the performance of supply chain processes and finances in the supply chain, and the enablers and inhibitors for the implementation of SCF instruments by the different actors. The authors focused on understanding the five key constructs (i.e., supply chain finance actors, supply chain finance instruments, supply chain processes and triggers, supply chain finance adoption, and its financial benefits) as well as its archetypes (i.e., relationship between supply chain finance archetypes and actors, relationship between supply chain finance archetypes, instruments, and triggers, relationship between supply chain finance archetypes and adoption, relationship between supply chain finance archetypes and financial benefits, and a brief summary on the supply chain finance archetypes). Through this systematic literature review, the authors paved the way to address the key gaps in supply chain actors, instruments, adoption, triggers, and financial benefits. Also, a conceptual framework was generated to be used for empirical validations based on a case study or qualitative comparative analysis. Finally, practical knowledge can be drawn from the analysis of financial benefits and the enablers and inhibitors of supply chain finance instruments implementation.

Oliveira et al. (2018) conducted a systematic literature review along with a proposed leangreen qualitative model for new product development (NPD) operations. The authors investigated the adherence of both lean and green practices in developing new products with respect to a two-way perspective (i.e., lean and green). 16 lean and green enablers for product development were presented and further evaluated using analytic hierarchy process (AHP) and fuzzy technique for order of preference by similarity to ideal solution (fuzzy TOPSIS) under a practical case of small and medium-sized enterprises (SMEs) in Brazil. It was found that among the lean and green enablers for NPD, product variety management and existence of strong project managers appeared to be a central element for SMEs to consider lean and green operations at the development stage of products. As a way forward, the authors suggested longitudinal studies to explore the relationships among enablers and how each affects the decision of NPD managers in SMEs.

\section{Emerging production development} issues

Various papers put forward scholarly efforts on investigating emerging production development issues such as improving performance, supply chain management, and economic and environmental viability of solution approaches. Such papers significantly provided inputs to the managers particularly in the manner of responding to issues that industries face nowadays.

Tseng et al. (2018) dealt with the issue on linking supply chain finance (SCF) and sustainable development (SD) by introducing a model to identify the decisive decision-making model for sustainable supply chain finance (SSCF) and the attributes to be improved to enhance SSCF in the industry at large. With the application of fuzzy TOPSIS, the authors found that enhancing the economic aspect of SSCF would lead to a significant influence on both the social and environmental aspects. Furthermore, the results of the decision-making model also pointed out stakeholder engagement as one of 
the most important driving criteria of SSCF together with buyer-supplier partnership level, stakeholder and customer satisfaction, inventory control, and raw material procurement in order. By creating an atmosphere of valuable relationships among stakeholders (e.g., buyer, supplier, firms-customers), capabilities of the decision making process regarding firm SSCF can be potentially increased. Lastly, to better frame the concept of SSCF and enhance the decisionmaking accuracy, they suggested conducting future studies involving a wider range of aspects and criteria under investigation, representative experts from various countries, multiple industries, the inclusion of social media data, and more hybrid methods.

In the context of environmental soundness and economic effectiveness in the production and operations management umbrella, studies conducted by Song et al. (2018) and Hasegawa et al. (2019) contributed largely in understanding the role of environment and economy in decisions related to improving performance in general. For one, Song et al. (2018) referred to the theory on total factor productivity (TFP) to analyze the impact of fiscal decentralization and environmental regulation on assessing economic and environmental development in a region using a slacks-based measure model. The specific discussion of this paper presented that of visibility function, production function, budget constraint, and the TFP model. As a major finding, the authors found that the influences of the other control variables on green TFP behave differently as evidenced by the alternating decline and increase of green TFP as the local economy develops.

On the other hand, Hasegawa et al. (2019) argued that the environmental impact of a life cycle option should be considered as equally important as the optimal cost for disassembly methods. Therefore, the authors looked into the life cycle option selection based on the multivalue circulation model with objective functions being on optimized cost and recycling rates. By employing a 0-1 integer programming model and $\varepsilon$-constraint method in cases of Japan and Germany in the life cycle option selection problem, they found that by fixing values of constraints enabling the solution of the life cycle option in the considered Pareto front, managers can compare solutions and draw conclusions out of it. Also, the type of material can significantly cause large differences between recovery and saving rates.

In another study, Okoshi et al. (2019) analyzed the cause and effect relationships among the performance dimensions and decision areas of high-performance manufacturing companies based on factor analysis and multiple linear regression. By establishing the connection between operations strategy and performance results, a systemic view with respect to the effects on performance by capabilities and policies can be mapped. The authors confirmed that structural and infrastructural aspects of the decision areas have a significant influence on the performance construct regardless of the nature of the performance dimension. Moreover, highperformance manufacturing companies pose a greater number of connections in quality, cost, speed, and dependability compared to innovation and flexibility performance variables.

A framework based on customer co-creation, strategic intent, and technology mapping was proposed by Tan et al. (2019) in order to guide Chinese manufacturers in considering the implementation of service value chain for sustainable service solutions including capabilities needed and technology required. It is found that one means to provide better services to customers was to personalize their needs based on personal information. Aside from that, servitization was recognized as a strategy to extend new offerings of firms based on current core competencies such that competitive advantage among rival entities is maintained. As for the technology-aspect of servitization, it was highlighted to integrate apps and websites to better entice customers for repeat transactions by providing better experience and services.

Finally, Wohlers et al. (2019) assessed the quality of a mechatronic system by using concepts of key performance indicators (KPIs). It was strongly positioned that the KPIs, being quantitative indicators, can statistically measure the core of the product's functionalities which in turn can determine atomically the extent of product fulfillment with respect to its required functionalities. The authors presented the foundations on quality control and condition 
monitoring as well as the KPI-based monitoring and control of mechatronic systems in production processes. By employing the KPIbased approach for monitoring and controlling production processes in a mechatronic system, business case estimations and reports about lessons learned were provided for cases in automated teller machines and beer brewing.

\section{Solution approaches to production research challenges}

Relevant challenges for production research including decision-making for maintaining reasonable investments and economic efficiency, keeping appropriate product design according to the requirements of customers, and assessing process capability, among others have prompted the need for sound solution approaches in order to support the decision-making of stakeholders especially in the manufacturing sector. Thus, this VSI selected papers that can provide insights about these pertinent production research concerns with the use of extended methodological approaches and some other novel models.

Bogataj et al. (2019) investigate the possible investment in collaborative robots in lieu of inevitably ageing workforce. It was, however, asserted by the authors that firms may pursue investing in collaborative robots or encouraging an early retirement program among industrial workers on the grounds of cost implications. Furthermore, the proposed simulation model was suggested to be used for evaluating investments in ergonomics of workplaces or finding a balance in the combination of pension schemes and investments in advanced support systems such as cooperative robots.

In another study, Palominos et al. (2019) presented a methodology based on the use of Kano's design (Kano et al., 1984) and quality function deployment (QFD) (Hauser \& Clausing, 1988) to capture the voice of the clients representing the flexibilities associated with the manufacture of a product. In order to illustrate the proposed methodology, a case study in a clothing company in Chile was conducted. It was found that the most important attributes that customers prefer go beyond the manufacturability capabilities of the clothing company under study; therefore, suppliers were urged to satisfy the requirements according to specifications. While the proposed methodology was able to systematically reflect the voice of the clients in the product design, the authors suggested developing supplementary methodologies that can transform the results of the flexibility requirements into more operational information.

Using a mathematical model, a multi-factorial analysis, and analysis of variance (ANOVA), the applicability of a vertical lift module (VLM) system was explored by Calvazara et al. (2019). In specific, the authors looked into the use of a VLM system and traditional warehouse with carton racks under various circumstances. A key result in the application of the method, showed that VLM was only suitable over a warehouse with carton racks under two distinct cases: first, when products considered are slow mobbing, that is, having high picking times, and when the cost of space is high of which available space is intended for other value-added activities. Finally, the model can be further extended for the design and sizing of storage solutions as it was believed to contribute to the economic modeling of particularly small items order picking systems.

On the other hand, a meta-heuristic method, genetic algorithm was introduced by Zhang et al. (2018) to obtain a near-optimal solution with a reasonable computational cost. This method was applied to solve the economic viability of sizing an onsite generation system (OGS) for manufacturing in the context of critical peaking pricing (CPP) demand program. The authors were able to arrive at an appropriate sized OGS which significantly reduces electricity billing cost under the CPP demand response program. Other than the CPP program, they suggested to also examine different demand response programs considering other sources of energy such as solar photovoltaic and wind turbines. Moreover, model-wise, the dataset used should have a considerable size so the proposed model can run on stochastic inputs and further arrive at relevant statistical results.

Another mathematical model - a mixedinteger linear programming model - was proposed by Banguera et al. (2018) to solve a capacitated facility problem. In this study, it 
aimed to determine the collection centers and the reprocessing plants of the system such that maximum benefit is achieved and the minimum investment is made. As such, the results revealed that a regulatory level framework can be imposed on a set of collection goals and penalties for the management. This study, however, did not include robust and stochastic scenario analyses, thus it was suggested by the authors to expand the model accordingly. This revised model will allow for additional information on waste generation and recycling goals once a collection center is made known.

Also focusing on the logistics side of management, Joshi and Gupta (2019) introduced an advanced-remanufacturing-to-orderdisassembly-to-order systems model to assess the effects of product design on recovery operations using linear physical programming. The model was designed to achieve financial, environmental, and physical goals. To better understand how the model worked, a sample case study on different laptop designs was considered. A major result showed that some designs were prominently more preferred for disassembly and remanufacturing than other designs. With such results, the most efficient product design for product recovery as specific areas of concern in reverse logistics and end-of-life product management can be determined.

For another, Chen et al. (2019) modified the fuzzy testing method developed by Buckley (2005) and further created a Six Sigma fuzzy evaluation index and testing model. The authors believed that process quality needs to be assessed using fuzzy calculations that is not difficult to process and at the same time obtain results that were not approximate values only. With the proposed Six Sigma quality index and fuzzy testing model, it verified that the process performance of an uncertain data for the case company under study does not meet the requirement of the quality level at 5 sigma disparate to the results obtained using the traditional testing method of process capability.

A similar study on the development of a methodology involving a process yield index was presented by Wang and Chen (2019). In this study, a new asymmetric process yield index was proposed as a Six Sigma measuring and analytical tool which goal was to analyze, improve, and control the measures of quality improvement. By employing this method, samples which follow a non-normal or skewed distribution, or is small in size, can be evaluated in terms of process information performance. However, since process distribution was not known in advance, fuzzy set theory or other similar algorithms can be combined to optimize the model's process accuracy.

Tomohiro et al. (2019) also developed a double sampling control chart based on the Taguchi index which features a judgment rule that was independent of the first sampling made. The design of the double sampling control chart for economical operation purposes was presented in detail taking note of the sampling costs and extra loss associated with the model. The authors confirmed that the proposed double sampling control chart can operate more economically and strictly compared to the single sampling control chart. Moreover, they suggested to simultaneously adopt two control charts for monitoring processes as well as to implement the proposed method in a case environment in the manufacturing sector.

At a manufacturing line level, Stadnicka and Litwin (2019) looked into the development of an integrated value stream map, value stream analysis, and system dynamics approach concept for minimizing work indispensable to perform complex analysis in a manufacturing setting. Through a new way of presenting an extended value stream map, benefits for computer simulation as a lean manufacturing tool can be obtained. The proposed methodology was able to identify manufacturing lines that need to be balanced and allocate spare capacity for the manufacture of other kinds of products. Nevertheless, the methodology was not suggested for unit production analysis and at the same time stands incapable to examine the impacts of some other manufacturing problems in the wider process efficiency area.

\section{Exploratory new investigation in the field \\ Understanding the complex nature of production research issues requires}


comprehensive conceptual investigations and methodologies that can provide valuable insights to decision-makers regarding the potential impact of these issues in the general operations and management of firms. Working under this principle, this VSI included some works that not only delivered timely and significant theoretical ideas and practical applications to production research issues but also provided lessons learned from the use of both mainstream and novel approaches.

Dekkers et al. (2019) attempted to connect theories of networked firms under integrated management of SCF. The authors strongly believed that while network theory has been implicitly adopted for SCF, theoretical foundations were still insufficient. Therefore, they contributed to the extant literature by first, presenting theoretical conceptualizations that allow researchers to confer with theoretical evidence in investigating SCF phenomena and focusing on the relationships between these theories and phenomena. The main managerial implication drawn from this study pointed out the need for alignment between buyers and suppliers and that of different company departments. Additionally, there exists a hindrance in collaboration and coordination among employees who has different functions within a firm. As a resolution, knowledge about SCF through various capacity-building activities should be pushed forward. As an extension to this study, they suggested to underscore the theoretical conceptualizations framed in another geographical context and to consider additional firm theories. Also, an amalgamation of theories needs to be considered while using a different methodology to extract the views of firms on SCF.

In another aspect of the supply chain, Pirttilä et al. (2019) examined the relevance of transaction cost theory (TCE) for supporting working capital management (WCM) which was enabled by financial supply chain analysis. As an empirical setting to measure and control the effectiveness of WCM on relative ratios, the authors have selected the Russian automotive industry being a very challenging environment with different types of social and individual networks and even informal relationships. This study has identified a few remarkable points in terms of theoretical and practical lenses. First, with the use of cash conversion cycles (CCC) as a metric for WCM models, the results showed a fluctuating CCC ratio across all stages under investigation which represents the unreliability of forecasting tied-up working capital by sales. Second, WCM was found to be more efficient in the supply chain of the Russian automotive industry than in Western Europe. Third, the proposed theoretical approach generally described the complex interdependencies of WCM components, thereby, provided relevant insights on how TCE was linked with WCM.

Aside from these insights on addressing widerange production research issues, five others produced novel works in developing prominent approaches and research directions in the context of advanced manufacturing technology, decision sciences, and production and operations management. One of which includes the work of Otsuka and Nagata (2018) proposing a simultaneous design method of target dimensions and process indices (i.e., $C p, C p k, C c$, and $C p m$ ). Considering both tolerance stack-up and tolerance allocation as major issues in applying the statistical tolerance index to actual design processes, a Monte-Carlo simulation and realcoded genetic algorithm using the UNDX crossover process was used to obtain approximate solutions to stack-up and allocation problems. The authors confirmed that the proposed method allowed designers to design process capability indices according to customer requirements for product performance and manufacturing cost. However, due to the limits of accuracy in machining, the cost function in the model was defined as the inverse of the allowable area that is uniformly evaluated. A more suitable evaluation function was recommended to be explored as a further study.

Another work that displayed novelty was that of Chan et al. (2018) which focused on investigating the innovative use of $3 \mathrm{D}$ printing (3DP) processes and its corresponding challenges as well as its legal implications in the industry. The authors carried out a qualitative empirical approach to understand the low adoption rate of 3DP technology in the industry and the protection of 3DP content in order to facilitate further innovative applications of 3DP. It was found that 3DP technology cannot yet handle 
mass-scale applications. In addition, the demand for mass customization characterized by 3DP shall complement that of mass production type of methods rather than entirely phasing it out as a production strategy. Therefore, with the perceived emerging use of 3DP technology, protecting its IP was believed to be a pertinent concern.

In the context of enhancing a strategy map, Moraga et al. (2020) presented a technique of combining qualitative and quantitative-based approaches in constructing a strategy map. While there exists no evidence in the literature supporting that one approach (i.e., qualitative, quantitative) was a better concept than the other, in this paper, it took advantage of the synergy and advantages offered by both approaches. Thus, the authors specifically utilized balanced scorecards and decision-making trial and evaluation laboratory (DEMATEL) to establish a strategy map according to each approach and further evaluate these maps through cluster analysis. This then resulted in a combined strategy map which provides conceptual support to managers in terms of focus on an objective under a particular perspective. They believed that the concept of combining a qualitative and quantitative strategy map holds significance due to the insights it can provide to managers, though other decision-making and cluster analysis tools were suggested to be explored.

Facchini et al. (2020) developed a mathematical model to optimize the interintraterminal flows of containers for stocking in ports. The authors specifically aimed to minimize the overall running costs and the carbon footprint index to support an efficient flow of containers in a terminal. A computational algorithm for non-linear programming serving as a foundation of the model was implemented in a multi-terminal maritime system in the Port of Bari, Italy. Several key findings were drawn from the results obtained. For one, when a specific distance is reached within a port, the use of a dry port no longer allowed the reduction of costs due to handling issues. For another, when the number of containers to be handled is very low, the model suggested storing all containers in the seaport to achieve a cost-effective configuration. Finally, the model developed confirmed to be useful in identifying the optimal configuration of containers to minimize cost and environmental impact. Though useful, the model was not able to suggest a unique configuration considering both cost and environmental impact altogether.

On the other hand, Kluczek (2019) proposed a methodology framework for assessing sustainable energy production systems by introducing sustainability improvements under an energy-oriented approach. In this paper, a comprehensive review of sustainability assessment methods was presented to justify the suitability of using data envelopment analysis slacks-based measure (DEA-SBM) and life cycle analysis (LCA)-based methods to verify energy efficiency and assess energy impact minimization via an integrated manner. As a result of employing the integrated methodology, the authors arrived at two major contributions of this work in the aspect of theory and practice. First, they found the relationship between having a lower value of economic dimension to energy losses and environmental costs. Second, energymakers can make reasonable decisions when the method incorporates process level including mitigating of adverse energy-related effects. As a further study, the authors suggested to also put emphasis on the other aspects of sustainability such as social implications as well as the analysis of technical solutions and associated parameters for reducing energy intensity and environmental damages.

\section{Synthesis on the issues and solution approaches on production research}

The VSI introduced contributions in literature review, thematic analyses, and methodological advances in the sub-fields of supply chain network, new product development, environmental and economically viable issues, service value chain, simulation, machine learning, and mathematical modeling, process quality models, and sustainable energy systems. These production research topics were revisited under the emerging sustainable development environment and machine learning era, and explicitly exhibited how new challenges in the forthcoming production research era brought opportunities for the production to play a proactive role. The new environment and tool both shaped a new feasible opportunistic region that provide a more efficient, effective, inclusive, 
sustainable, and satisfactory outcome to the general production research community. These new environment and tools are depicted in Fig. 1.

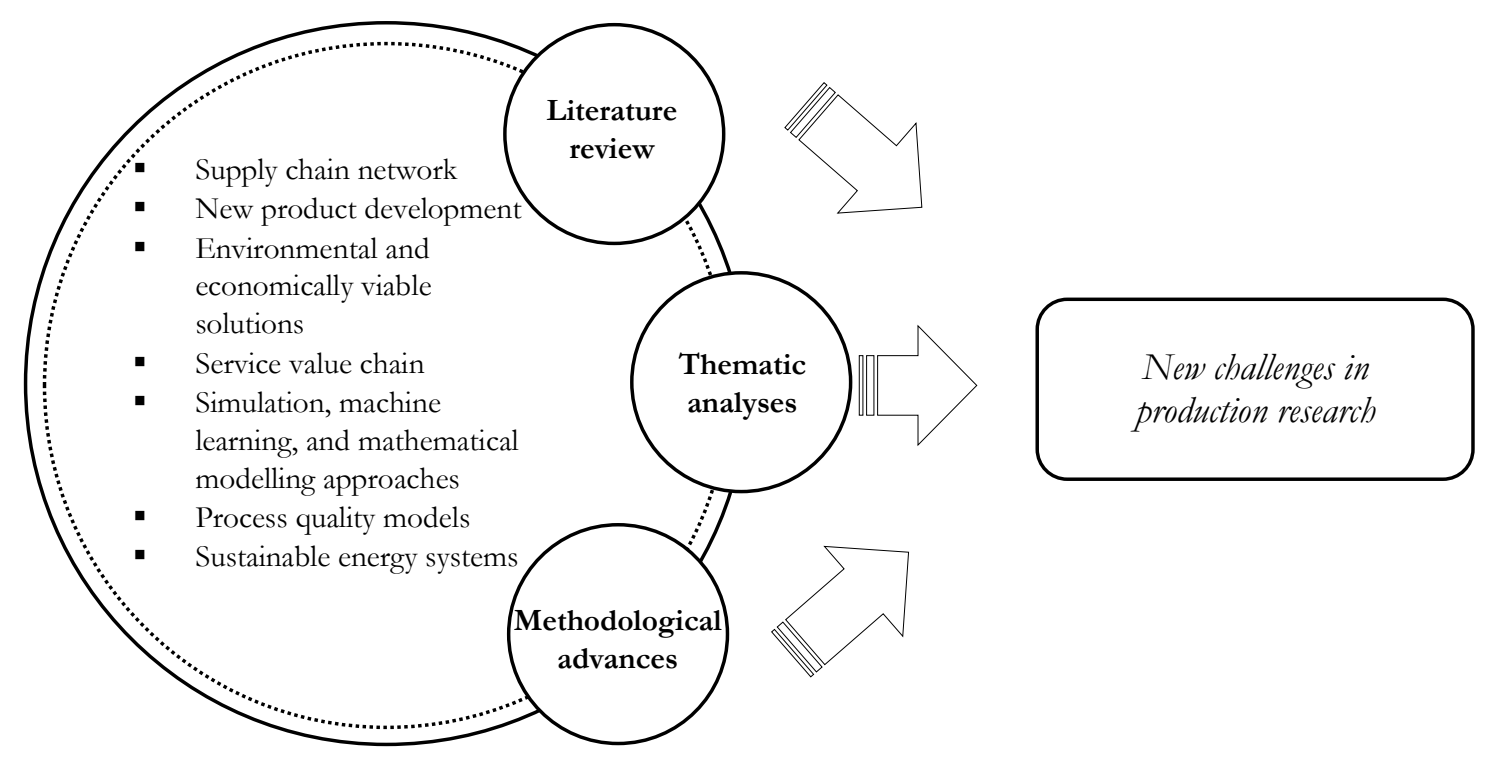

Fig. 1: The new production research challenges

\section{Acknowledgment}

The editorial team would like to thank International Foundation for Production Research (IFPR) Fellow Prof. Christopher O'Brien and IJPE editors-in-chief Robert Grubbstrom and Stefan Minner for the leadership and coordination. Miss Miriam Bongo also provided much needed editorial support in various means to the team.

\section{References}

Banguera, L. A., Sepúlveda, J. M., Ternero, R., Vargas, M., \& Vásquez, Ó. C. (2018). Reverse logistics network design under extended producer responsibility: The case of out-of-use tires in the Gran Santiago city of Chile. International Journal of Production Economics, 205(August), 193-200.

Bogataj, D., Battini, D., Calzavara, M., \& Persona, A. (2019). The ageing workforce challenge: Investments in collaborative robots or contribution to pension schemes, from the multi-echelon perspective. International Journal of Production Economics,
210(December 2018), 97-106.

Buckley, J.J., 2005. Fuzzy statistics: hypothesis testing. Soft Computing, 9 (7), 512-518.

Calzavara, M., Sgarbossa, F., \& Persona, A. (2019). Vertical Lift Modules for small items order picking: an economic evaluation. International Journal of Production Economics, 210(May 2018), 199-210.

Chakuu, S., Masi, D., \& Godsell, J. (2019). Exploring the relationship between mechanisms, actors and instruments in supply chain finance: A systematic literature review. International Journal of Production Economics, 216(May 2018), 35-53.

Chan, H. K., Griffin, J., Lim, J. J., Zeng, F., \& Chiu, A. S. F. (2018). The impact of 3D Printing Technology on the supply chain: Manufacturing and legal perspectives. International Journal of Production Economics, 205(August), 156-162.

Chen, K. S., Wang, C. H., Tan, K. H., \& Chiu, S. F. (2019). Developing one-sided specification six-sigma fuzzy quality index and testing model to measure the process performance of fuzzy information. 
International Journal of Production Economics, 208(57), 560-565.

Dekkers, R., de Boer, R., Gelsomino, L. M., de Goeij, C., Steeman, M., Zhou, Q., Sinclair, S., Souter, V. (2019). Evaluating Theoretical Conceptualisations for Supply Chain and Finance Integration: A Scottish Focus Group. International Journal of Production Economics. https://doi.org/10.1016/j.ijpe.2019.07.024

Facchini, F., Digiesi, S., \& Mossa, G. (2020). Optimal dry port configuration for container terminals: A non-linear model for sustainable decision making. International Journal of Production Economics, 219(April 2019), 164-178.

Hasegawa, S., Kinoshita, Y., Yamada, T., \& Bracke, S. (2019). Life cycle option selection of disassembly parts for materialbased CO 2 saving rate and recovery cost: Analysis of different market value and labor cost for reused parts in German and Japanese cases. International Journal of Production Economics, 213(May 2018), 229242.

Hauser, J., Clausing, D. (1988). The House of Quality. Harvard Business Review. pp. 6373 May-Jun.

Joshi, A. D., \& Gupta, S. M. (2019). Evaluation of design alternatives of End-of-Life products using internet of things. International Journal of Production Economics, 208(May 2018), 281-293.

Kano, N., Seraku, N., Takahashi, F., Shinichi, T. (1984). Attractive quality and must-be quality. Journal of the Japanese Society for Quality Control 14 (2), 39-48 (in Japanese).

Kluczek, A. (2019). An energy-led sustainability assessment of production systems - An approach for improving energy efficiency performance. International Journal of Production Economics, 216(April 2018), 190203.

Moraga, J. A., Quezada, L. E., Palominos, P. I., Oddershede, A. M., \& Silva, H. A. (2020). A quantitative methodology to enhance a strategy map. International Journal of Production Economics, 219(May 2019), 43-53.

Okoshi, C. Y., de Lima, E.P., \& Da Costa, S. E.G. (2019). Performance cause and effect studies: Analyzing high performance manufacturing companies. International Journal of Production Economics, 210(April 2018), 27-41.

Oliveira, G.A., Tan, K.H., \& Guedes, B.T. (2018). Lean and green approach: An evaluation tool for new product development focused on small and medium enterprises. International Journal of Production Economics, 205(August), 62-73.

Otsuka, A., \& Nagata, F. (2018). Quality design method using process capability index based on Monte-Carlo method and realcoded genetic algorithm. International Journal of Production Economics, 204(July), 358-364.

Palominos, P., Quezada, L. E., \& Gonzalez, M. A. (2019). Incorporating the voice of the client in establishing the flexibility requirement in a production system First phase Product features Second phase House of flexibility. International Journal of Production Economics, 211(November 2018), 34-43.

Pirttilä, M., Virolainen, V.M., Lind, L., Kärri, T. (2019). Working capital management in the Russian automotive industry supply chain.. International Journal of Production Economics. https://doi.org/10.1016/j.ijpe.2019.08.009

Song, M., Du, J., \& Tan, K. H. (2018). Impact of fiscal decentralization on green total factor productivity. International Journal of Production Economics.

https://doi.org/10.1016/j.ijpe.2018.09.019

Stadnicka, D., \& Litwin, P. (2019). Value stream mapping and system dynamics integration for manufacturing line modelling and analysis. International Journal of Production Economics, 208(April 2018), 400-411.

Tan, K. H., Ji, G., Chung, L., Wang, C. H., Chiu, A., \& Tseng, M. L. (2019). Riding the wave of belt and road initiative in servitization: Lessons from China. International Journal of Production Economics, 211(May 2018), 15-21.

Tan, K.H., Ji, G., Chung, L., Wang, C., Chiu, A., \& Tseng, M. L. (2019). Riding the wave of belt and road initiative in servitization: Lessons from China. International Journal of Production Economics, 211(January), 15-21.

Tomohiro, R., Arizono, I., Takemoto, Y. (2019). Economic design of double sampling Cpm 
control chart for monitoring process capability. International Journal of Production Economics.

https://doi.org/10.1016/j.ijpe.2019.08.003

Tseng, M.-L., Wu, K.-J., Hu, J., \& Wang, C.-H. (2018). Decision-making model for sustainable supply chain finance under uncertainties. International Journal of Production Economics, 205(November 2018), 30-36.

Wang, C., \& Chen, K. (2020). New process yield index of asymmetric tolerances for bootstrap method and six sigma approach. International Journal of Production Economics, 219(April 2019), 216-223.

Wohlers, B., Dziwok, S., Pasic, F., Lipsmeier, A., \& Becker, M. (2019). Monitoring and control of production processes based on Key Performance Indicators for mechatronic systems. International Journal of Production Economics. https://doi.org/10.1016/j.ijpe.2019.07.025

Zhang, Y., Islam, M. M., Sun, Z., Yang, S., Dagli, C., \& Xiong, H. (2018). Optimal sizing and planning of onsite generation system for manufacturing in Critical Peaking Pricing demand response program. International Journal of Production Economics, 206(August), 261-267. 